\title{
Challenges in the clinical measurement of ocular surface disease in glaucoma patients
}

This article was published in the following Dove Press journal:

Clinical Ophthalmology

31 October 20 I I

Number of times this article has been viewed

\author{
Stephen C Pflugfelder' \\ Christophe Baudouin ${ }^{2,3}$ \\ 'Ophthalmology-Ocular Surface \\ Center, Baylor College of Medicine, \\ Houston, TX, USA; ${ }^{2}$ Department \\ of Ophthalmology, Quinze-Vingts \\ Hospital, Paris, France; ${ }^{3}$ Vision \\ Institute, Paris, France
}

\begin{abstract}
Ocular surface disease (OSD) is common among glaucoma patients. Clinical assessment of OSD can be challenging. This review focuses on some of the limitations relating to both subjective and objective measures of OSD, including dry eye. A survey of the literature was conducted to identify the caveats associated with different methods of assessing OSD. The effect of preservatives on the ocular surface, with respect to glaucoma patients in particular, was also reviewed. Objective methods for assessing ocular surface health and disease include the Schirmer test, tear break-up time, fluorescein turnover, corneal and conjunctival staining, tear osmolarity, and vital dyes. These measures all have limitations in terms of their ability to grade the severity of OSD. Previous studies using the OSD Index showed a mild-to-moderate correlation to dry eye disease severity. Other scoring systems for dry eye have shown a relationship to patient symptom scores or quality of life. Due to the challenges clinicians face concerning both subjective and objective ocular surface health assessments, discerning clinical improvement in ocular surface disease can be a challenge. Further research is needed in order to optimize existing clinical methods and/or identify alternative techniques for assessing OSD in the glaucoma population.
\end{abstract}

Keywords: dry eye, glaucoma, ocular surface disease, ocular surface disease index, preservatives, tear break-up time

\section{Glaucoma and ocular surface disease (OSD)}

Glaucoma is an optic neuropathy that is most often associated with elevated intraocular pressure (IOP). The most widely prescribed therapies are topical ocular drops. Prostaglandin analog (PGA) and beta-blockers are typically the initial medications of choice. ${ }^{1}$

Animal and human tissue studies have shown that pathologic changes to the ocular surface, conjunctiva, and trabecular meshwork can occur as a result of long-term exposure to preservatives in the topical medication formulation. ${ }^{2}$ The contribution of the active ingredients to these adverse effects cannot be ruled out. For example, even nonpreserved IOP-lowering medications, such as timolol, can increase the expression of immunoinflammatory markers and cytokines (human leukocyte antigen-DR region [HLA-DR], interleukin [IL]-6, and IL-8) in the conjunctival epithelium of glaucoma patients. ${ }^{3}$ Glaucoma patients often take multiple IOP-lowering drops in order to adequately control their IOP. Therapeutic regimens with multiple medications can increase patients' potential exposure to preservatives even further.

Rossi et al investigated the presence of dry eye syndrome in 61 patients with ocular hypertension or glaucoma taking one to three drops of topical IOP-lowering medications
Correspondence: Christophe Baudouin Department of Ophthalmology, Quinze-Vingts Hospital, 28 Rue de Charenton, Paris, 75012, France

Tel +33 | 4002 I 304

$\mathrm{Fax}+33$ | 4002 । 399

Email baudouin@quinze-vingts.fr 
per day and 20 patients not taking medications (control group). ${ }^{4}$ Dry eye syndrome was defined as concomitant reduced tear break-up time (TBUT) and punctate keratitis. Approximately $40 \%$ of those taking two or three drops per day had dry eye syndrome, compared with $11 \%$ of those taking one drop per day and $5 \%$ of the control group. The OSD Index (OSDI) questionnaire, which will be discussed in more detail later, was used in this study. Moderate-to-severe OSDI scores were observed for approximately $30 \%$ of glaucoma patients taking two or more drops per day. Because many IOP-lowering medications contain benzalkonium chloride (BAK), patients can be exposed to a considerable "BAK load" over their lifetimes.

Recent studies have examined the prevalence of OSD in glaucoma and ocular hypertensive patients. Leung et al conducted a study on 101 glaucoma patients in order to ascertain the prevalence of OSD. ${ }^{5}$ A majority of patients $(59 \%)$ in this study reported symptoms of dry eye (via the OSDI). Schirmer tests showed $61 \%$ of the patients had a decrease in tear production. Positive results for corneal and conjunctival lissamine green staining were found in about $22 \%$ of the patients. Abnormal tear quality (reduced TBUT) was observed in $78 \%$ of patients.

Fechtner and colleagues also measured the prevalence of OSD in 630 patients from ten clinical sites. ${ }^{6}$ Their study found that $48.4 \%$ of the patients had some degree of OSD (mild, moderate, or severe). OSD symptom severity was positively correlated with the number of topical IOP-lowering medications administered. It is evident that the rates of OSD are higher for glaucoma patients treated with two or three medications than with monotherapy. Unfortunately, patients with pre-existing tear dysfunction may be even more susceptible to preservative toxicity.

A large-scale survey of 4107 patients measured the incidence of ocular toxicity caused by preservatives in IOPlowering medications. ${ }^{7}$ Eighty-four percent of the patients used preserved eyedrops. All ocular symptoms were more prevalent in the patients who took preserved topical drops compared with those who only received preservative-free medications $(P<0.001)$. These symptoms included discomfort upon instillation, foreign body sensation, dry eye sensation, burning-stinging, tearing, and eyelid itching. Patients on preserved eyedrops had a more than twofold increased incidence of ocular signs. As one might expect, the prevalence of ocular signs and symptoms increased with the number of preserved drops in the therapeutic regimen.

Another multicenter epidemiologic survey conducted in Europe compared the prevalence of side effects between preserved and nonpreserved topical beta-blockers for a group of nearly 10,000 patients. ${ }^{8}$ Ocular side effects such as foreign body sensation, discomfort upon instillation, stinging-burning, and dry eye sensation were significantly more frequent in the preserved eyedrops group $(P<0.0001)$. BAK was the most commonly used preservative in topical IOP-lowering formulations at that time. ${ }^{9}$

A large retrospective analysis of over 20,000 patients found that glaucoma and ocular hypertension patients on a regimen of either latanoprost preserved with BAK or travoprost-Z preserved with SofZia ${ }^{\circledR}$ Preservative System (Alcon Laboratories, Inc, Fort Worth, TX) showed no significant difference in the rates of dry eye, ocular infection, or OSD over a 1-year period. Limitations of this claims-based study are its relatively short duration, lack of randomization, and inability to account for sample or overthe-counter use. ${ }^{10}$

A large-scale study from Germany, involving 20,506 patients, sought to analyze the links between glaucoma, dry eye, age, medication, and concomitant disease. ${ }^{11}$ Among individuals with glaucoma, more women than men were reported to develop dry eye ( $56.9 \%$ and $45.7 \%$, respectively). The difference in the frequency of dry eye between men and women became more obvious after age 50 years. Hypertension, diabetes mellitus, and dry mouth, nose, and skin were the most frequent concomitant systemic diseases found in the survey. The incidence of dry eye increased with age, the number of IOP-lowering medications, and the duration of glaucoma.

The relatively high prevalence of OSD among glaucoma patients becomes apparent when one compares these rates to those in the general population. A cross-sectional survey among 25,444 men in the United States found that the prevalence of dry eye disease increased with age from about 3.9\% among men aged 50-54 years to 7.7\% among those aged $\geq 80$ years. ${ }^{12}$ A survey of nearly 40,000 women in the United States reported that $5.7 \%$ of women $<50$ years old suffered from dry eye syndrome, compared with $9.8 \%$ of women $\geq 75$ years of age. ${ }^{13}$ These rates are considerably lower than those previously mentioned for patients on IOPlowering medications.

\section{The effect of preservatives on the ocular surface}

OSD and inflammation have long been associated with the chronic use of IOP-lowering medications and especially the preservatives contained in their formulations. ${ }^{7,14,15}$ A recent review suggested that long-term use of topical eyedrops can induce a host of ocular surface effects such as ocular 
discomfort, conjunctival inflammation, subconjunctival fibrosis, epithelial apoptosis, tear film instability, corneal surface impairment, and the increased risk of failure for glaucoma surgery. ${ }^{15}$

BAK is the most commonly used preservative in topical ocular medications. ${ }^{9,15,16}$ BAK has been shown to remain in corneal tissues for an extended period of time. In vivo rabbit studies found that BAK was detectable in the cornea and conjunctival tissues up to 7 days following instillation of a single $30 \mu \mathrm{L}$ drop. ${ }^{17}$

BAK is known to disrupt tight junctions in the epithelial layer of the cornea. ${ }^{18}$ Pauly et al conducted studies with a human reconstituted corneal epithelial model to measure the effect of increasing concentrations $(0.001 \%-0.5 \%)$ of BAK for 24 hours on the expression and distribution of the tight junction protein, occludin. ${ }^{19}$ BAK caused a disappearance of occludin in the superficial layers of the corneal epithelial model that was dose dependent.

The effect of BAK on corneal barrier function has been assessed by measuring the change in transepithelial electric resistance (TER) of rabbit corneas in vivo. ${ }^{20,21} \mathrm{BAK}(0.05 \%)$ caused an immediate decrease in TER. ${ }^{20}$ Later experiments using this model system reported dose-dependent decreases in TER upon exposure to concentrations ranging from $0.02 \%-0.005 \%{ }^{21}$ These BAK concentrations are comparable to those found in marketed IOP-lowering medications. ${ }^{9,16}$

Preclinical studies have examined the effect of BAK on the ocular surface. Detrimental effects on human conjunctival cell (Wong-Kilbourne derivative of Chang conjunctiva) viability and membrane integrity were observed upon exposure to PGA formulations containing BAK. ${ }^{22}$ In addition, apoptosis and necrosis increased upon exposure of the cells to BAK. In another set of experiments, growth arrest and apoptotic cell death occurred in a dose-dependent manner 24-72 hours after exposure. ${ }^{23}$ Debbasch et al, using this same conjunctival cell line, found that apoptosis occurred at lower concentrations of BAK while necrotic processes were observed at higher concentrations of this agent. ${ }^{24}$ They also demonstrated the production of reactive oxygen species following exposure of the cells to BAK. Ayaki and Iwasawa reported lower cell viability for human conjunctival, rabbit corneal, and bovine corneal cells exposed to varying dilutions of PGA formulations preserved with BAK. ${ }^{25}$

Another study showed a decrease in human corneal epithelial cell viability on exposure to a PGA topical formulation containing BAK. ${ }^{26} \mathrm{~A}$ dose-dependent decrease in cell survival was observed with treatment of human corneal and conjunctival cells of increasing
BAK concentrations. ${ }^{27}$ Travoprost with $0.015 \%$ BAK was shown to have a higher proportion of viable cells compared to its vehicle, however. This cytoprotective effect was reported by Guenoun and colleagues with both travoprost and latanoprost. ${ }^{28}$ Epstein et al found elevated amounts of the inflammatory mediators such as tumor necrosis factor, C-reactive protein, IL-1, IL-10, and IL-12 in corneal and conjunctival epithelial cells exposed to BAK. ${ }^{29} \mathrm{BAK}$ at $0.25 \%$ and $0.5 \%$ appeared to cause a loss of goblet cells, increases in corneal thickness, apoptosis, corneal inflammation, and neovascularization in another rat model..$^{30}$ In addition, Kahook and Noecker reported that once-daily administration of latanoprost with $0.02 \%$ BAK caused a loss of corneal goblet cells in a rabbit model. ${ }^{31}$

The deleterious effects of BAK have been investigated in human clinical trials. Reductions in TBUT were observed both 3 hours and 3 days following dosing with BAKpreserved carteolol. ${ }^{32}$ Patients who received topical timolol preserved with BAK at $0.01 \%$ and $0.04 \%$ had lower Schirmer test values, shorter TBUTs, reduced goblet cell densities, and a greater amount of epithelial cell squamous metaplasia when compared with healthy age-matched patients in the control group. ${ }^{33}$ Arici and colleagues also observed deleterious effects of this preservative on Schirmer and tear break-up tests. ${ }^{34}$ Another clinical study found that chronic dosing of timolol maleate, preserved with BAK, caused damage to the ocular surface, most notably the mucus layer of the tear film. ${ }^{35}$

Martone et al evaluated the effects of chronic administration of preserved IOP-lowering medications on the ocular surface. ${ }^{36}$ Patients were divided into six groups based on their medication regimen. The preserved medication groups showed reductions in Schirmer I scores, esthesiometry, TBUT, superficial corneal epithelial cell density, and the number of subbasal nerves compared to the normal patients and those on preservative-free medications.

Several alternative preservatives have been developed in an attempt to minimize the toxic effects of BAK. Purite is an oxidative preservative that is used in brimonidine topical drops and artificial tears. ${ }^{37}$ A clinical study with brimonidine-purite $0.15 \%$ found that the majority of conjunctival hyperemia and allergic conjunctivitis adverse events were mild. ${ }^{38}$

Polyquad $^{\circledR}$ (polyquarternium-1) is a polycationic preservative that is contained in formulations of contact lens disinfecting solutions ${ }^{39}$ and artificial tears. ${ }^{40}$ Labbe and colleagues showed that Polyquad induced considerably less toxicity than BAK in vivo. ${ }^{41}$ Polyquad produced similar 
results to the control for the tear production test, slit-lamp, fluorescein evaluation, and histology.

SofZia, mentioned previously, is a preservation system that is contained in the travoprost topical ophthalmic formulation, Travatan Z. ${ }^{16,42}$ In vitro studies using Chang conjunctival cells showed no significant effect on cellular viability and membrane integrity. ${ }^{22}$ No cytotoxicity was observed in cells incubated in travoprost with SofZia. Ayaki and Iwasawa reported that corneal and conjunctival cells exposed to varying dilutions $(1 \times, 2 \times$, and $10 \times)$ of travoprost preserved with SofZia (10, 30, and 60 minutes) had the highest viability of any of the PGA formulations tested. ${ }^{25}$ This formulation also did not increase apoptosis or necrosis. Lewis and colleagues reported that, during the course of a 3-month study, travoprost $0.004 \%$ with SofZia was well tolerated in glaucoma patients. $^{42}$ Only one (1/344) patient experienced mild corneal staining. Ocular hyperemia occurred at an incidence of $6.4 \%$. No treatment-related serious adverse events occurred during the study.

\section{Challenges of measuring OSD in glaucoma patients Objective measures}

Clinical methods of assessing physiologic functions that contribute to ongoing ocular surface health as well as disease have been developed over the past decades. Schirmer I (without anesthesia; Schirmer II is performed with anesthesia) consists of placing a filter paper strip on the lower lid margin in the temporal position of an unanesthetized patient. ${ }^{43}$ This continues to be a useful test for the clinician; however, the length of time required for the procedure is a disadvantage as it causes discomfort to the patient often resulting in reflex tearing which impacts the variability of the data.

Several diagnostic tests evaluate the quantity and quality of the tear film. The measurement of TBUT following the instillation of a fluorescein dye is a widely used clinical technique. ${ }^{44}$ Nichols et al found the TBUT analysis to be more reproducible than the Schirmer test. ${ }^{45}$ A number of factors can reduce the utility of this test in the clinical trial setting. These confounding factors can include: heterogeneous populations, variations in measurements and scoring, concomitant medications, comorbid diseases that affect the ocular surface, and environmental differences. If permanent damage to the tear-producing cells or glands has occurred, then it will be difficult to show any improvement in TBUT, regardless of the therapy or preservative. In addition, it is known that fluorescein can destabilize the tear film. ${ }^{46}$ Efforts to minimize these variables, when possible, increase the ability of the TBUT analysis to discriminate between groups of varying OSD severity. One study reported that mean TBUT improved from 2.02 seconds to 6.34 seconds after a change in IOP-lowering therapy from a PGA preserved with BAK to one preserved with SofZia $(P<0.001) .{ }^{47}$

Other methods have been used to measure the clearance or turnover of fluorescein instilled into the tears. These can include direct fluorometric analysis of fluorescein in the precorneal tear film or the inferior tear meniscus. The fluorescein clearance test (FCT) was found to be better at predicting ocular irritation than the Schirmer I test. The FCT also had a higher correlation with meibomian gland dysfunction. ${ }^{48}$ Applying a correction factor from Schirmer I to the FCT further improved its correlations with meibomian gland dysfunction and ocular irritation symptoms. ${ }^{49}$

Stains and vital dyes have been used with relatively good success in clinical practice. Fluorescein, lissamine green, and rose bengal stains, for example, have utility for assessing the health of the ocular surface. A number of factors can reduce the utility of these tests in the clinical trial setting. These confounding factors can include: heterogeneous populations, variations in measurements and scoring, and environmental influences. These techniques have limitations, as they tend to measure the extent of ocular surface damage from dry eye and are relatively insensitive in the early stages of dry eye disease.

Clinicians often rely on the presence of ocular irritation symptoms, the Schirmer test, TBUT, and ocular surface vital dyes to diagnose tear dysfunction. More sophisticated clinical tests are currently available, which may have greater sensitivity for detecting OSD in glaucoma patients, but they are currently not widely available. One such technique for evaluating the health of the ocular surface (such as dry eye) is computerized videokeratoscopy. ${ }^{50-52}$ This diagnostic tool utilizes computer algorithms for analyzing Placido rings that reflect off the surface of the cornea. Other noninvasive techniques, such as aberrometry, ${ }^{53}$ have proven to be useful for assessing ocular surface health.

Confocal microscopy has been used in recent years for evaluating ocular surface health. Using this technique, mean individual epithelial cell area and nucleocytoplasmic ratios were found to be worse in dry eye patients. ${ }^{54}$ Benítezdel-Castillo et al reported that dry eye patients had a reduced density of corneal epithelial cells and a decrease in the number of subbasal nerves. ${ }^{55}$ Another study using confocal 
microscopy reported that the clinical scores were significantly lower in the preserved medication group $(P<0.05)$ compared to those for the nonpreserved group. Superficial corneal epithelial cell density was reduced in all patients on IOPlowering medications (except for the preservative-free group $[P>0.05])$ compared to control subjects $(P<0.001)$.

Impression cytology, a method to sample the conjunctival epithelium, has been used to study the underlying causes of OSD. The expression of inflammatory markers such as HLA-DR was measured in patients taking topical IOP-lowering medications using this technique. ${ }^{56}$ HLA-DR was higher in these patients than in either allergic patients or normal volunteers.

Sullivan and colleagues recently conducted a prospective study of 299 patients across 10 sites in the United States and European Union that examined the clinical value of tear osmolarity and several other tests for evaluating the severity of dry eye disease. ${ }^{57}$ The rank order of correlation coefficients to disease severity, from highest to lowest, was osmolarity $\left(r^{2}=0.55\right)$, conjunctival staining $\left(r^{2}=0.47\right)$, corneal staining $\left(r^{2}=0.43\right)$, meibomian score $\left(r^{2}=0.37\right)$, TBUT $\left(r^{2}=0.30\right)$, and Schirmer test $\left(r^{2}=0.17\right)$. Interestingly, disease severity was poorly classified using a combination of clinical thresholds for about $63 \%$ of patients with mildto-moderate dry eye.

\section{Subjective measures}

Several survey instruments have been developed for assessing ocular surface health. The McMonnies Dry Eye Questionnaire is a subjective method of assessing ocular health from the patient's perspective. ${ }^{58,59}$ This patient-reported outcome instrument was designed to differentiate dry eye patients from those with a normal ocular surface.

An OSD-specific questionnaire has been developed (OSD-QoL) to evaluate health-related quality of life. ${ }^{60}$ This instrument was developed in France and consists of a diagnostic aid and a subjective section that relates to treatment, perception of treatment, and quality of life.

\section{The OSDI}

Another subjective measurement tool for assessing symptoms of OSD is the OSDI. ${ }^{61-63}$ The instrument consists of 12 questions that are designed to provide a quick assessment of ocular irritation symptoms related to dry eye disease and their effect on vision-related functioning. ${ }^{61}$ The 12 items of the OSDI questionnaire are graded on a scale of $0-4$ as follows: $0=$ none of the time; $1=$ some of the time; $2=$ half of the time; $3=$ most of the time; and $4=$ all of the time. The total OSDI score is calculated according to the following formula: OSDI $=([$ sum of scores for all questions answered $] \times 100) /$ ([total number of questions answered] $\times 4$ ). The overall OSDI score is based on a scale from $0-100$, which is defined as follows: $0-12=$ normal; $13-22=$ mild OSD; $23-32=$ moderate OSD; 33-100 = severe OSD.

A factor analysis of the OSDI indicated that there were three different subscales within the questionnaire including: ocular symptoms, environmental triggers, and vision-related function. ${ }^{61} \mathrm{~A}$ Cronbach $\alpha$ analysis indicated a high degree of internal consistency in all three of the subscales as well as the OSDI total score overall. The OSDI scores have been shown to correlate with McMonnies questionnaire and the National Eye Institute Visual Functioning Questionnaire-25. Some differences do exist between these measures due to the fact that the OSDI is specific for dry eye disease. This instrument was previously validated in a dry eye patient population. ${ }^{61}$ To the authors' knowledge, the OSDI is yet to be validated for use specifically with glaucoma patients.

Some investigators have examined the correlation between the OSDI and symptoms of dry eye and OSD. Versura et al reported significant correlations between the OSDI subjective symptoms and tear osmolarity for patients with mild $(r=0.313)$ and moderate $(r=0.462)$ OSD. ${ }^{64}$ However, the correlation was not significant for patients with severe OSD $(r=0.09)$. Within normal-to-moderate dry eye cohorts, Sullivan et al found the following correlation coefficient to disease severity: osmolarity $\left(r^{2}=0.55\right)$, conjunctival staining $\left(r^{2}=0.47\right)$, corneal staining $\left(r^{2}=0.43\right)$, OSDI $\left(r^{2}=0.41\right)$, meibomian score $\left(r^{2}=0.37\right)$, TBUT $\left(r^{2}=0.30\right)$, and Schirmer result $\left(r^{2}=0.17\right) .{ }^{57}$ Valente and colleagues measured the signs and symptoms of tear film dysfunction using the OSDI in patients on ocular hypotensive drops containing BAK. ${ }^{65}$ Approximately half $(26 / 50,52 \%)$ of the patients on an ocular hypotensive regimen containing BAK showed symptoms of tear film dysfunction. Signs of OSD appeared to be greater in patients on more than two topical medications. Signs and symptoms of OSD were correlated for patients on monotherapy consisting of $\beta$-adrenergic antagonists.

Some caveats to consider with the OSDI are the natural fluctuations in dry eye symptoms. ${ }^{61}$ Walker et al found significant differences in study participants' reporting of visual function in the OSDI depending on the time of day. ${ }^{66}$ They found more visual function limitations relating to dry eye symptoms (eg, working on the computer, driving, watching television) in the evening than in the morning. 
Another factor that may complicate the assessment of dry eye using the OSDI is corneal hypoesthesia. Bourcier and colleagues have shown that corneal sensitivity tends to decrease with age ${ }^{67}$ Furthermore, patients with dry eye were shown to have higher thresholds for thermal, chemical, and mechanical stimulation than their normal counterparts. Benítz-del-Castillo confirmed that sensitivity to these stimuli was reduced, which was attributed to a decreased number of subbasal corneal nerves. ${ }^{55}$ Martone and colleagues showed that the reduction in the number of subbasal nerves was associated with a decrease in corneal sensitivity for patients on IOP-lowering therapies preserved with BAK. ${ }^{36}$ This decrease in corneal sensitivity may interfere with a patient's perception of dry eye symptoms and therefore confound the interpretation of results from the OSDI.

Miller and colleagues recently conducted a study with 310 patients to determine the minimal clinically important difference for the OSDI. ${ }^{63} \mathrm{~A}$ subject global assessment and a clinician global impression served as the basis for estimating the minimal clinically important difference for the overall OSDI scores (range 0-100). The subject global assessment and clinician global impression correlated with the change in OSDI score for all categories except for the normal category. The range of minimal clinically important difference values was 4.5-7.3 for mild and moderate disease, and 7.3-13.4 for severe disease.

Several confounding factors may cause measurements, using the OSDI in large-scale clinical trials that are well controlled, randomized parallel groups masked with prospectively-stated statistical objectives, to be problematic. The studies often consist of heterogeneous populations from disparate study sites. There are individual variations in each patient's response to their dry eye symptoms. Concomitant medications or comorbid diseases can also affect the ocular surface health. This is particularly true of patients with glaucoma, who are usually elderly and on multiple chronic topical ocular drops. Longer treatment periods are often needed in order to see improvements in their ocular surface health. Differences in climate across study sites can also affect the outcome. The positive placebo effect can confound the evaluation of the patient response to treatment. Since the OSDI measures ocular surface symptoms, it may not be able to show improvements in OSD per se.

One could expect that the likelihood of showing a difference for glaucoma patients with the OSDI between treatment groups might be higher if certain factors were considered in the study design. For example, study patients would be on therapy for extended treatment periods. The study populations could be limited to mild and moderate dry eye patients. No concomitant medications should be allowed. The studies could exclude other ocular disease states that can affect/exacerbate OSD. More sensitive parameters such as impression cytology could be used. Although difficult to incorporate all of these criteria, some study designs have attempted to mitigate confounding outcomes. ${ }^{47,68}$

\section{Clinical results with the OSDI}

Several investigators have been able to show differences with regard to the ocular surface health of patients with glaucoma by using the OSDI. Henry and colleagues conducted a multicenter study using the OSDI with patients who changed from their previous prostaglandin therapy to travoprost with SofZia. ${ }^{68}$ Glaucoma and ocular hypertensive patients included in this study were originally taking latanoprost or bimatoprost monotherapy and demonstrated a need for an alternative therapy due to tolerability issues. Overall OSDI scores were 12.0 for latanoprost, 13.2 for bimatoprost, and 8.7 for travoprost (after 8 weeks of travoprost treatment; $P<0.0001$ vs latanoprost; $P<0.0001$ vs bimatoprost). About $70 \%$ of the 253 patients with OSD symptoms at baseline had a decrease in symptom severity by at least one level (ie, a shift in symptom severity from moderate to mild) on the OSDI scale. It was possible to discern these differences successfully with the OSDI most likely due to the fact that the patients were experiencing some adverse effects with respect to tolerability at the baseline visit.

Horsley and Kahook evaluated glaucoma patients with the OSDI 8 weeks after they made a transition from latanoprost with $0.02 \%$ BAK to travoprost with SofZia. ${ }^{47}$ Patients were required to have a baseline TBUT $<6$ seconds and they were instructed to avoid using other topical drops during the study. At the 8-week time point they found that there were decreases in mean inferior corneal staining from 2.40 to $1.38(P<0.001)$ and mean OSDI scores from 26.31 to $16.56(P<0.001)$. In this trial, the ability of the OSDI to discriminate between the two groups was improved by a careful design of the protocol that attempted to minimize confounding factors (such as other topical medications).

Katz and colleagues measured the symptoms of OSD in patients with ocular hypertension or open-angle glaucoma that had been on BAK-preserved latanoprost $0.005 \%$ monotherapy for at least 1 month. ${ }^{69}$ The patients had baseline scores of $\geq 13$ on the OSDI. They were then randomly assigned to either continue with latanoprost therapy or transition to 
travoprost without BAK (preserved with SofZia). OSDI evaluations were repeated at 6 and 12 weeks. Mean OSDI scores at 12 weeks were significantly lower for patients with mild OSD in the travoprost $(11.6 \pm 10.8)$ group than in the latanoprost $(14.4 \pm 11.9)$ group $(P=0.04)$. Patients who had previously been treated with BAK-preserved latanoprost for $>24$ months were more likely to improve to a normal OSDI score after 12 weeks if they were transitioned to travoprost preserved without BAK $(P=0.03)$.

These clinical studies demonstrate, despite aforementioned issues with the application of the OSDI to differing patient populations and OSDI instrument caveats, that clinically significant differences in OSD symptoms can be identified with the OSDI. This tool continues to be used in clinical trials in an attempt to characterize the effect of different drugs, environmental factors, and diseases on the health of the ocular surface.

\section{Conclusion}

Due to challenges that clinicians face with both subjective and objective ocular surface health assessments, discerning clinical improvement in OSD can be a difficult task. Further work needs to be done to optimize existing clinical methods and/or identify alternative methods for assessing OSD in glaucoma patients.

\section{Acknowledgment}

Julie Crider provided medical writing assistance that was funded by Alcon Laboratories, Inc.

\section{Disclosures}

$\mathrm{SCP}$ received consulting fees from Alcon, Allergan, Bausch and Lomb, and GlaxoSmithKline and research grants from Allergan and GlaxoSmithKline. CB received consulting fees and research grants from Alcon, Allergan, MSD, Pfizer, Santen, and Thea.

\section{References}

1. McKinnon SJ, Goldberg LD, Peeples P, Walt JG, Bramley TJ. Current management of glaucoma and the need for complete therapy. $\mathrm{Am}$ J Manag Care. 2008;14(1 Suppl):S20-S27.

2. Baudouin C, Pisella PJ, Fillacier K, et al. Ocular surface inflammatory changes induced by topical antiglaucoma drugs: human and animal studies. Ophthalmology. 1999;106(3):556-563.

3. Baudouin C, Hamard P, Liang H, Creuzot-Garcher C, Bensoussan L, Brignole F. Conjunctival epithelial cell expression of interleukins and inflammatory markers in glaucoma patients treated over the long term. Ophthalmology. 2004;111(12):2186-2192.

4. Rossi GC, Tinelli C, Pasinetti GM, Milano G, Bianchi PE. Dry eye syndrome-related quality of life in glaucoma patients. Eur J Ophthalmol. 2009;19(4):572-579.

5. Leung EW, Medeiros FA, Weinreb RN. Prevalence of ocular surface disease in glaucoma patients. J Glaucoma. 2008;17(5):350-355.
6. Fechtner RD, Godfrey DG, Budenz D, Stewart JA, Stewart WC, Jasek MC. Prevalence of ocular surface complaints in patients with glaucoma using topical intraocular pressure-lowering medications. Cornea. 2010;29(6):618-621.

7. Pisella PJ, Pouliquen P, Baudouin C. Prevalence of ocular symptoms and signs with preserved and preservative free glaucoma medication. Br J Ophthalmol. 2002;86(4):418-423.

8. Jaenen N, Baudouin C, Pouliquen P, Manni G, Figueiredo A, Zeyen T. Ocular symptoms and signs with preserved and preservative-free glaucoma medications. Eur J Ophthalmol. 2007;17(3):341-349.

9. Novack GD, Evans R. Commercially available ocular hypotensive products: preservative concentration, stability, storage, and in-life utilization. J Glaucoma. 2001;10(6):483-486.

10. Schwartz GF, Kotak S, Mardekian J, Fain JM. Incidence of new coding for dry eye and ocular infection in open-angle glaucoma and ocular hypertension patients treated with prostaglandin analogs: Retrospective analysis of three medical/pharmacy claims databases. BMC Ophthalmol. 2011;11:14.

11. Erb C, Gast U, Schremmer D. German register for glaucoma patients with dry eye. I. Basic outcome with respect to dry eye. Graefes Arch Clin Exp Ophthalmol. 2008;246(11):1593-1601.

12. Schaumberg DA, Dana R, Buring JE, Sullivan DA. Prevalence of dry eye disease among US men: estimates from the Physicians' Health Studies. Arch Ophthalmol. 2009;127(6):763-768.

13. Schaumberg DA, Sullivan DA, Buring JE, Dana MR. Prevalence of dry eye syndrome among US women. Am J Ophthalmol. 2003;136(2): 318-326.

14. Detry-Morel M. Side effects of glaucoma medications. Bull Soc Belge Ophtalmol. 2006(299):27-40.

15. Baudouin C, Labbe A, Liang H, Pauly A, Brignole-Baudouin F. Preservatives in eyedrops: the good, the bad and the ugly. Prog Retin Eye Res. 2010;29(4):312-334

16. Yee RW. The effect of drop vehicle on the efficacy and side effects of topical glaucoma therapy: a review. Curr Opin Ophthalmol. 2007;18(2): 134-139.

17. Champeau EJ, Edelhauser HF. Effect of ophthalmic preservatives on the ocular surface: conjunctival and corneal uptake and distribution of benzalkonium chloride and chlorhexidine digluconate. In: Holly F, Lamberts D, MacKeen D, editors. The Preocular Tear Film in Health, Disease, and Contact Lens Wear. Lubbock, TX: Dry Eye Institute, Inc: 1986:292-302.

18. Kaur IP, Lal S, Rana C, Kakkar S, Singh H. Ocular preservatives: associated risks and newer options. Cutan Ocul Toxicol. 2009;28(3):93-103.

19. Pauly A, Meloni M, Brignole-Baudouin F, Warnet JM, Baudouin C. Multiple endpoint analysis of the 3D-reconstituted corneal epithelium after treatment with benzalkonium chloride: early detection of toxic damage. Invest Ophthalmol Vis Sci. 2009;50(4):1644-1652.

20. Uematsu M, Kumagami T, Kusano M, et al. Acute corneal epithelial change after instillation of benzalkonium chloride evaluated using a newly developed in vivo corneal transepithelial electric resistance measurement method. Ophthalmic Res. 2007;39(6):308-314.

21. Kusano M, Uematsu M, Kumagami T, Sasaki H, Kitaoka T. Evaluation of acute corneal barrier change induced by topically applied preservatives using corneal transepithelial electric resistance in vivo. Cornea. 2010;29(1):80-85.

22. Baudouin C, Riancho L, Warnet JM, Brignole F. In vitro studies of antiglaucomatous prostaglandin analogues: travoprost with and without benzalkonium chloride and preserved latanoprost. Invest Ophthalmol Vis Sci. 2007;48(9):4123-4128.

23. De Saint Jean M, Brignole F, Bringuier AF, Bauchet A, Feldmann G, Baudouin C. Effects of benzalkonium chloride on growth and survival of Chang conjunctival cells. Invest Ophthalmol Vis Sci. 1999;40(3): 619-630.

24. Debbasch C, Brignole F, Pisella PJ, Warnet JM, Rat P, Baudouin C. Quaternary ammoniums and other preservatives' contribution in oxidative stress and apoptosis on Chang conjunctival cells. Invest Ophthalmol Vis Sci. 2001;42(3):642-652. 
25. Ayaki M, Iwasawa A. Cytotoxicity of prostaglandin analog eye drops preserved with benzalkonium chloride in multiple corneoconjunctival cell lines. Clin Ophthalmol. 2010;4:919-924.

26. Yee RW, Norcom EG, Zhao XC. Comparison of the relative toxicity of travoprost $0.004 \%$ without benzalkonium chloride and latanoprost $0.005 \%$ in an immortalized human cornea epithelial cell culture system. Adv Ther. 2006;23(4):511-519.

27. Ammar DA, Noecker RJ, Kahook MY. Effects of benzalkonium chloride-preserved, polyquad-preserved, and sofZia-preserved topical glaucoma medications on human ocular epithelial cells. Adv Ther. 2010;27(11):837-845.

28. Guenoun JM, Baudouin C, Rat P, Pauly A, Warnet JM, BrignoleBaudouin $\mathrm{F}$. In vitro comparison of cytoprotective and antioxidative effects of latanoprost, travoprost, and bimatoprost on conjunctivaderived epithelial cells. Invest Ophthalmol Vis Sci. 2005;46(12): 4594-4599.

29. Epstein SP, Chen D, Asbell PA. Evaluation of biomarkers of inflammation in response to benzalkonium chloride on corneal and conjunctival epithelial cells. J Ocul Pharmacol Ther. 2009;25(5):415-424.

30. Pauly A, Brignole-Baudouin F, Labbe A, Liang H, Warnet JM, Baudouin C. New tools for the evaluation of toxic ocular surface changes in the rat. Invest Ophthalmol Vis Sci. 2007;48(12):5473-5483.

31. Kahook MY, Noecker R. Quantitative analysis of conjunctival goblet cells after chronic application of topical drops. Adv Ther. 2008;25(8): 743-751.

32. Baudouin C, de Lunardo C. Short-term comparative study of topical $2 \%$ carteolol with and without benzalkonium chloride in healthy volunteers. Br J Ophthalmol. 1998;82(1):39-42.

33. Yalvac IS, Gedikoglu G, Karagoz Y, et al. Effects of antiglaucoma drugs on ocular surface. Acta Ophthalmol Scand. 1995;73(3):246-248.

34. Arici MK, Arici DS, Topalkara A, Guler C. Adverse effects of topical antiglaucoma drugs on the ocular surface. Clin Experiment Ophthalmol. 2000;28(2):113-117.

35. Herreras JM, Pastor JC, Calonge M, Asensio VM. Ocular surface alteration after long-term treatment with an antiglaucomatous drug. Ophthalmology. 1992;99(7):1082-1088.

36. Martone G, Frezzotti P, Tosi GM, et al. An in vivo confocal microscopy analysis of effects of topical antiglaucoma therapy with preservative on corneal innervation and morphology. Am J Ophthalmol. 2009;147(4):725-735. e1.

37. Katz LJ. Twelve-month evaluation of brimonidine-purite versus brimonidine in patients with glaucoma or ocular hypertension. J Glaucoma. 2002;11(2):119-126.

38. Mundorf T, Williams R, Whitcup S, Felix C, Batoosingh A. A 3-month comparison of efficacy and safety of brimonidine-purite $0.15 \%$ and brimonidine $0.2 \%$ in patients with glaucoma or ocular hypertension. J Ocul Pharmacol Ther. 2003;19(1):37-44.

39. Codling CE, Maillard JY, Russell AD. Aspects of the antimicrobial mechanisms of action of a polyquaternium and an amidoamine. $J$ Antimicrob Chemother. 2003;51(5):1153-1158.

40. Ubels JL, Clousing DP, Van Haitsma TA, et al. Pre-clinical investigation of the efficacy of an artificial tear solution containing hydroxypropylguar as a gelling agent. Curr Eye Res. 2004;28(6):437-444.

41. Labbe A, Pauly A, Liang H, et al. Comparison of toxicological profiles of benzalkonium chloride and polyquaternium-1: an experimental study. J Ocul Pharmacol Ther. 2006;22(4):267-278.

42. Lewis RA, Katz GJ, Weiss MJ, et al. Travoprost $0.004 \%$ with and without benzalkonium chloride: a comparison of safety and efficacy. J Glaucoma. 2007;16(1):98-103.

43. Karampatakis V, Karamitsos A, Skriapa A, Pastiadis G. Comparison between normal values of 2- and 5-minute Schirmer test without anesthesia. Cornea. 2010;29(5):497-501.

44. Khanal S, Tomlinson A, McFadyen A, Diaper C, Ramaesh K. Dry eye diagnosis. Invest Ophthalmol Vis Sci. 2008;49(4):1407-1414.

45. Nichols KK, Mitchell GL, Zadnik K. The repeatability of clinical measurements of dry eye. Cornea. 2004;23(3):272-285.
46. Patel S, Murray D, McKenzie A, Shearer DS, McGrath BD. Effects of fluorescein on tear breakup time and on tear thinning time. Am J Optom Physiol Opt. 1985;62(3):188-190.

47. Horsley MB, Kahook MY. Effects of prostaglandin analog therapy on the ocular surface of glaucoma patients. Clin Ophthalmol. 2009;3: 291-295.

48. Afonso AA, Monroy D, Stern ME, Feuer WJ, Tseng SC, Pflugfelder SC. Correlation of tear fluorescein clearance and Schirmer test scores with ocular irritation symptoms. Ophthalmology. 1999;106(4): 803-810.

49. Macri A, Pflugfelder S. Correlation of the Schirmer 1 and fluorescein clearance tests with the severity of corneal epithelial and eyelid disease. Arch Ophthalmol. 2000;118(12):1632-1638.

50. Liu Z, Pflugfelder SC. Corneal surface regularity and the effect of artificial tears in aqueous tear deficiency. Ophthalmology. 1999;106(5): 939-943.

51. de Paiva CS, Lindsey JL, Pflugfelder SC. Assessing the severity of keratitis sicca with videokeratoscopic indices. Ophthalmology. 2003;110(6):1102-1109.

52. Alonso-Caneiro D, Iskander DR, Collins MJ. Assessment of tear film surface quality using dynamic-area high-speed videokeratoscopy. IEEE Trans Biomed Eng. 2009;56(5):1473-1481.

53. Szczesna DH, Alonso-Caneiro D, Iskander DR, Read SA, Collins MJ. Predicting dry eye using noninvasive techniques of tear film surface assessment. Invest Ophthalmol Vis Sci. 2011;52(2):751-756.

54. Kojima T, Matsumoto Y, Dogru M, Tsubota K. The application of in vivo laser scanning confocal microscopy as a tool of conjunctival in vivo cytology in the diagnosis of dry eye ocular surface disease. Mol Vis. 2010;16:2457-2464.

55. Benitez-Del-Castillo JM, Acosta MC, Wassfi MA, et al. Relation between corneal innervation with confocal microscopy and corneal sensitivity with noncontact esthesiometry in patients with dry eye. Invest Ophthalmol Vis Sci. 2007;48(1):173-181.

56. Baudouin C, Liang H, Bremond-Gignac D, et al. CCR 4 and CCR 5 expression in conjunctival specimens as differential markers of $\mathrm{T}(\mathrm{H}) 1 /$ $\mathrm{T}(\mathrm{H}) 2$ in ocular surface disorders. JAllergy Clin Immunol. 2005;116(3): 614-619.

57. Sullivan BD, Whitmer D, Nichols KK, et al. An objective approach to dry eye disease severity. Invest Ophthalmol Vis Sci. 2010;51(12): $6125-6130$

58. McMonnies CW, Ho A. Responses to a dry eye questionnaire from a normal population. J Am Optom Assoc. 1987;58(7):588-591.

59. McMonnies CW, Ho A. Patient history in screening for dry eye conditions. J Am Optom Assoc. 1987;58(4):296-301.

60. Baudouin C, Creuzot-Garcher C, Hoang-Xuan T, et al. Creating a specific diagnostic and quality-of-life questionnaire for patients with ocular surface disease. J Fr Ophtalmol. 2003;26(2):119-130. French.

61. Schiffman RM, Christianson MD, Jacobsen G, Hirsch JD, Reis BL. Reliability and validity of the Ocular Surface Disease Index. Arch Ophthalmol. 2000;118(5):615-621.

62. Ozcura F, Aydin S, Helvaci MR. Ocular surface disease index for the diagnosis of dry eye syndrome. Ocul Immunol Inflamm. 2007;15(5): 389-393.

63. Miller KL, Walt JG, Mink DR, et al. Minimal clinically important difference for the ocular surface disease index. Arch Ophthalmol. 2010;128(1):94-101.

64. Versura P, Profazio V, Campos EC. Performance of tear osmolarity compared to previous diagnostic tests for dry eye diseases. Curr Eye Res. 2010;35(7):553-564.

65. Valente C, Iester M, Corsi E, Rolando M. Symptoms and signs of tear film dysfunction in glaucomatous patients. J Ocul Pharmacol Ther. 2011;27(3):281-285.

66. Walker PM, Lane KJ, Ousler GW 3rd, Abelson MB. Diurnal variation of visual function and the signs and symptoms of dry eye. Cornea. 2010;29(6):607-612. 
67. Bourcier T, Acosta MC, Borderie V, et al. Decreased corneal sensitivity in patients with dry eye. Invest Ophthalmol Vis Sci. 2005;46(7): 2341-2345.

68. Henry JC, Peace JH, Stewart JA, Stewart WC. Efficacy, safety, and improved tolerability of travoprost BAK-free ophthalmic solution compared with prior prostaglandin therapy. Clin Ophthalmol. 2008;2(3): $613-621$.
69. Katz G, Springs CL, Craven ER, Montecchi-Palmer M. Ocular surface disease in patients with glaucoma or ocular hypertension treated with either BAK-preserved latanoprost or BAK-free travoprost. Clin Ophthalmol. 2010;4:1253-1261.

\section{Publish your work in this journal}

Clinical Ophthalmology is an international, peer-reviewed journal covering all subspecialties within ophthalmology. Key topics include: Optometry; Visual science; Pharmacology and drug therapy in eye diseases; Basic Sciences; Primary and Secondary eye care; Patien Safety and Quality of Care Improvements. This journal is indexed on

Submit your manuscript here: http://www.dovepress.com/clinical-ophthalmology-journal

\section{Dovepress}

PubMed Central and CAS, and is the official journal of The Society of Clinical Ophthalmology (SCO). The manuscript management system is completely online and includes a very quick and fair peer-review system, which is all easy to use. Visit http://www.dovepress.com/ testimonials.php to read real quotes from published authors. 